BULLETIN Bulletin hispanique

HISPANIQUE Université Michel de Montaigne Bordeaux

117-1 | 2015

Les poètes des rhéteurs

\title{
Cervantes desde la retórica
}

viaje al centro del canon

Rosa María Aradra Sánchez

\section{(2) OpenEdition}

Journals

Edición electrónica

URL: https://journals.openedition.org/bulletinhispanique/3820

DOI: 10.4000/bulletinhispanique.3820

ISSN: $1775-3821$

Editor

Presses universitaires de Bordeaux

Edición impresa

Fecha de publicación: 1 junio 2015

Paginación: 209-228

ISBN: 979-10-300-0174-7

ISSN: 0007-4640

Referencia electrónica

Rosa María Aradra Sánchez, «Cervantes desde la retórica», Bulletin hispanique [En línea], 117-1 | 2015,

Publicado el 01 junio 2018, consultado el 12 febrero 2022. URL: http://journals.openedition.org/

bulletinhispanique/3820 ; DOI: https://doi.org/10.4000/bulletinhispanique.3820

Tous droits réservés 


\title{
Cervantes desde la retórica: viaje al centro del canon
}

\author{
Rosa María Aradra Sánchez \\ Universidad Nacional de Educación a Distancia
}

Cet article analyse la réception de Cervantès dans les principaux traités de rhétorique espagnole allant du XVII ${ }^{\mathrm{e}}$ siècle jusqu'au début du XIX ${ }^{\mathrm{e}}$ siècle. Son objet est de déterminer quand et dans quelles circonstances Cervantès a été érigé en modèle par la rhétorique, sur la base de quels critères et avec quelles implications.

Mots-clés : Cervantès, rhétorique, canon, roman, $\mathrm{XVII}^{\mathrm{e}}$ siècle, $\mathrm{XVIII}{ }^{\mathrm{e}}$ siècle.

Este trabajo analiza la recepción de Cervantes en la retórica española desde los tratados más importantes del siglo XVII hasta principios del siglo XIX. El propósito es determinar cuándo y en qué circunstancias es canonizado por la retórica, desde qué criterios y con qué valores.

Palabras clave: Cervantes, retórica, canon, novela, siglo XVII, siglo XVIII.

This paper analyses the reception of Cervantes in the Spanish rhetoric, from the major treatises of the seventeenth century until the early nineteenth century. Its purpose is to determine when and in what circumstances Cervantes was canonized by Rhetoric, on what basis and with what implications.

Keywords: Cervantes, rhetoric, canon, novel, seventeenth century, eighteenth century.

\footnotetext{
A unque el campo de acción de la retórica ha sido tradicionalmente el discurso persuasivo, oratorio y comunicativo en sentido amplio, sabido es que sus conexiones con la poética y con la literatura han estado presentes casi desde sus mismos orígenes, en una prolongada serie de intereses compartidos y de influencias recíprocas. Desde esta perspectiva, constituye un espacio de gran interés a la hora de profundizar en los procesos de formación del canon literario,
} 
no solo por su atención a las prácticas estilísticas de los poetas y de los géneros cultivados por ellos, sino también de los prosistas, excluidos normalmente del radio de acción de las poéticas.

En este terreno sabemos de numerosos trabajos sobre la retórica implícita y explícita en la escritura cervantina, sobre la influencia de la teoría retórica y poética en Cervantes ${ }^{1}$, pero no son tantos los que se han planteado la recepción del autor del Quijote en los tratados de retórica. En el panorama general del estudio de la recepción cervantina, tan desarrollado en unos aspectos y tan falto de estudios todavía desde otras perspectivas ${ }^{2}$, el objetivo de este trabajo es paliar parte de este vacío analizando la presencia de Cervantes en la retórica española, desde su tiempo hasta principios del XIX. Para ello nos proponemos hacer un seguimiento de las preceptivas de los siglos XVII y XVIII con el propósito de determinar cuándo y en qué circunstancias es canonizado por la retórica, desde qué criterios y con qué valores. El resultado nos iluminará algo más sobre la recepción por esta vía de uno de los autores más tempranamente situados en el centro del canon de la prosa de ficción castellana, pero también sobre cómo la retórica se convierte en vehículo de valores literarios contemporáneos, sobre cómo los asocia a una tradición y los actualiza.

\section{CERVANTES Y LA RETÓRICA DEL SIGLO XVII}

En la red de relaciones inherente a todo proceso canonizador no siempre resulta fácil determinar en qué medida la «institucionalización» de un autor por la vía de la preceptiva poética o retórica favorece su difusión y consolidación en el canon, o, viceversa, de qué manera la difusión editorial y creciente conocimiento de la obra de un autor explica -entre otros factores- su inclusión teórica.

Con respecto a la producción cervantina, sabemos que el Quijote fue desde muy pronto un éxito editorial ${ }^{3}$, hasta el punto de convertirse en el primer tercio del siglo XVII en la obra más citada de entre todas sus contemporáneas (Montero Reguera 2005: 15-17).

Además, como recuerda Montero Reguera, es significativo que en fechas tan tempranas como 1624, ocho ańos después de la muerte de Cervantes, Tomás Tamayo de Vargas incluyera en la Junta de libros, una de las primeras bibliografías de la literatura española, unas líneas sobre Cervantes en las que ya apuntó el tópico de «ingenio lego», tan repetido después (Montero Reguera 2005: 22-23). Y tres décadas antes de que acabara el siglo, Nicolás Antonio le había dedicado una entrada extensa en su Bibliotheca Hispana Nova (1672),

1. Pueden verse, entre otros, los trabajos de Roldán (1975 y 1981), Blecua (1985), Artaza (1989 y 2008), López Grigera (1991 y 1994) y Martín Jiménez (2000).

2. Hace unas décadas ya destacó Montero Reguera (1997: 101-115) el poco interés despertado por el Quijote desde los presupuestos de la Estética de la Recepción.

3. Véanse los datos sobre su difusión que aporta Aguilar Piñal (1983). 
en la que valoraba por igual su producción en verso y en prosa, y le reconocía modelo admirable de oratoria:

Desde el tiempo en que alcanzó su madurez hasta prácticamente nuestros días tal vez haya habido alguien a él comparable en cuanto a excelencia de genio e imaginación, pero nadie superior; hábil como pocos en sus versos no menos que en su prosa. Nos ha dejado numerosas obras memorables las cuales llevan con pasión bajo el brazo aquellos que gustan de ejercitarse en el campo de nuestra oratoria y, en general, todos los aficionados al tono amable de sus obras, del país que sean (pues tienen casi todos los europeos en sus respectivos idiomas las más importantes de estas obras). (cit. Montero Reguera 2005: 25)

Sin embargo, esta difusión no parece reflejarse en la misma medida en la preceptiva retórica de su tiempo, en la que apenas lo encontramos citado.

Como punto de partida hay que tener en cuenta que la producción retórica del XVII continúa su castellanización de forma paralela a la paulatina incorporación de la literatura española a los tratados. En el contexto de una preceptiva muy arraigada al latín, de las tres retóricas castellanas del siglo anterior -la de Salinas (1541), Espinosa (1578) y Juan de Guzmán (1589)_ vamos a pasar a la publicación en castellano de aproximadamente dos tercios de las veinticuatro retóricas catalogadas en el siglo XVII (Galbarro García 2010: 74), hasta que la balanza se incline de forma definitiva hacia la lengua vernácula a lo largo del siglo XVIII (Aradra 1997: 56 y ss.).

De ahí que tengamos que reconocer a priori la escasa atención que va a recibir la literatura nacional en términos globales, y, más aún, una producción contemporánea que todavía no tiene la sanción de la autoridad imitativa que otorgaba el tiempo transcurrido a una teoría poco secularizada y sujeta, en la mayoría de los casos, a la moral del contexto educativo en el que se desarrolla. Por eso no es frecuente en tratados de este tipo acudir a ejemplos contemporáneos, aparte de los particulares del propio autor, como se puede constatar en la producción retórica de la época, en la que sobresalen los grandes autores latinos: Cicerón, Virgilio, Ovidio, etc.

La influencia que tiene la lengua del texto retórico en la elección de los ejemplos es también muy importante. Como es lógico, las retóricas en latín optaron principalmente por modelos clásicos grecolatinos, mientras que las castellanas incorporaron con más libertad, y en ocasiones no sin ciertos reparos, ejemplos de nuestra literatura nacional.

Entre las retóricas españolas del XVII que rompieron con esta tendencia sobresale la Elocuencia española en arte (1604 y 1621, en edición ampliada) de Bartolomé Jiménez Patón ${ }^{4}$, que acudió abiertamente a nuestra literatura para ejemplificar la elocución. Esta retórica, poco novedosa desde el punto de vista teórico, se centraba en la elocutio y en la actio, y esto favoreció que recurriera

4. La Elocuencia española en arte fue publicada por primera vez en Toledo, Thomás de Guzmán, 1604, y en 1621 fue reeditada y enmendada en el Mercurius Trimegistus, Baeza, Pedro de la Cuesta Gallo, con el título Libro de la elocuencia española en arte. Citamos por la edición de Francisco J. Martín (Jiménez Patón 1993). 
a los poetas de los siglos XVI y XVII para ilustrar los diferentes recursos de la elocutio. Este será uno de sus principales valores: «hablar de retórica española a españoles» (Martí 1972: 267).

La amplitud y variedad de sus citas, que convierten la obra en una extraordinaria antología de la poesía española, contrasta sin embargo con la escasa atención que prestó a la prosa. Entre sus menciones figuran la Celestina y el Lazarillo, pero no Cervantes ni el Quijote, aunque sí nombre a Fray Luis de Granada, Gonzalo de Illescas, Fray Luis de León, la Beata Teresa de Jesús, Fray Antonio de Guevara, Ambrosio de Morales, P. Mariana, Hernando del Castillo y Juan de Pineda. De ahí que se haya llamado la atención sobre esta significativa ausencia de Cervantes, así como de la prosa de Lope, a pesar de ser como poeta el autor más citado en su retóricas.

En esta primera mitad del XVII nos encontramos también con el que fuera considerado uno de los mejores tratados de retórica castellana de la época, que pronto contaría con las alabanzas de Gallardo y de Menéndez Pelayo: El culto sevillano de Juan de Robles. Escrito hacia 1631, e inédito hasta 1883, cuando fue publicado en la Colección de Bibliófilos Andaluces, tampoco contribuyó mucho a la difusión cervantina. En él seguía la técnica dialogada de Sánchez de Lima, el Pinciano o Cascales, con la idea de proporcionar las líneas generales de lo que debía ser un hombre de mundo, elocuente y culto, a modo de un tratado de educación.

Aunque entre los méritos de Juan de Robles se ha señalado su positiva valoración de los prosistas del XVI frente a los del XVII, no deja de mostrar algunas limitaciones en sus conocimientos de historia literaria, y los mismos prejuicios morales de la preceptiva de su tiempo hacia la narrativa realista. Esto explicaría el hecho de que no mencione al infante don Juan Manuel o La Celestina, y de que no solo omita las novelas pastoriles o picarescas, sino el mismo Quijote.

Son solo dos las ocasiones en las que se alude en El culto sevillano a Cervantes. En una censura la incultura de muchos jóvenes que afectan oscuridad y que «en habiendo leído a Guzmán de Alfarache o a Don Quijote [...] se sueñan catedráticos de Salamanca, y hablan en las materias con la libertad y autoridad que si lo fueran» (Robles 1883: 36-37). La otra referencia la encontramos cuando Juan de Robles confiesa su propósito de proteger la lengua española, «a quienes algunos caballeros desmesurados quieren hacer algunos tuertos y desaguisados» de la misma manera que hizo don Quijote con Dulcinea (Robles 1883: 294).

El que Juan de Robles se presente a sí mismo como un quijote que sale a defender la hermosura de la lengua espańola, metaforizada en su Dulcinea, revela el conocimiento generalizado de la obra al que hacíamos antes mención. Los ejemplos literarios y las observaciones bibliográficas con que explica los preceptos de la retórica le valieron a El culto sevillano la calificación de la primera

5. Así lo ha destacado Francisco J. Martín en su introducción (Jiménez Patón, 1993: 67-68). Véase también Rozas (1962). 
retórica crítica de la literatura española, en la que a la erudita valoración de autores y obras se sumaba una incipiente conciencia historiográfica (Vilanova 1953). Aunque Robles eludió a los autores contemporáneos para evitar las disputas gongorinas de la época, es en ese contexto donde cobra relieve la escasa atención dedicada a Cervantes en comparación con otros autores.

Otro silencio llamativo del autor del Quijote en el terreno de la preceptiva lo encontramos en la obra de un profesor de retórica y poética contemporáneo suyo, Baltasar Gracián. Su Arte de ingenio (1642), calificado de retórica conceptista, evita cualquier referencia a Cervantes. No obstante, hay que considerar que este silencio en las referencias literarias de Gracián no es el único; sorprende también que un escritor ascético y moralista como él no cite jamás a los grandes escritores místicos, y sí recuerde a ciertos escritores de novela picaresca, como Mateo Alemán ${ }^{6}$.

Con un enfoque escolar de menor entidad encontramos la retórica El Jardín de la Elocuencia de José Antonio Hebrera y Esmir (1677). Publicada con el propósito de reunir «flores» o adornos retóricos para consejo y ejemplo de oradores, poetas y políticos, destaca junto a la de Jiménez Patón en el panorama del XVII por el alto número de referencias literarias castellanas. Sin embargo, el que sus ejemplos fueran en su mayor parte de poetas espańoles barrocos del siglo XVII (Góngora y Lope sobre todo), y de dramaturgos (Calderón, Tirso...) dejó escaso margen de representación a la prosa cervantina, en la línea de las retóricas mencionadas (Monge 1986).

Fuera del ámbito estrictamente retórico, en la original miscelánea El Pasajero (1617) de Cristóbal Suárez de Figueroa podemos apreciar la generalizada opinión negativa que tiene entonces la preceptiva sobre las novelas, esas "patrańas y consejas, propias del brasero en tiempo de frío, que en suma vienen a ser unas bien compuestas fábulas, unas artificiosas mentiras» (Suárez de Figueroa 1913: 55). Su concepto de la novela diverge en gran medida del que tiene Cervantes: mientras que para este debían proscribirse de ella las sentencias de los filósofos, las fábulas de los poetas y las oraciones de los retóricos (prólogo de la I parte del Quijote), para Suárez de Figueroa (1913: 55), como vemos, la novela no había de ser simple, sino que tenía que acompañarse de sentencias que la dotaran de trasfondo filosófico. En la misma línea, en su Plaza universal de todas las ciencias y artes verá la lectura de novelas como una de las mañas o ardides de que se podía servir con éxito un alcahuete para rendir la honestidad femenina (Suárez de Figueroa 1615: 276) ${ }^{7}$.

Por otra parte, entre las diversas alusiones a Cervantes que se le han atribuido, y que lo han identificado con Avellaneda, se ha señalado aquella en la que censura a quienes llegan a escribir prólogos y dedicatorias antes de

6. Sobre la ocultación de Cervantes en Gracián se han pronunciado distintos estudiosos, especialmente en relación con el Criticón, como Peralta (1986). Véase también Correa Calderón (1970).

7. Sobre la lectura y fortuna de la novela en los siglos XVII y XVIII, véase López (1998). 
morir ${ }^{8}$. Incluso se ha visto una alusión a Cervantes cuando dice en El pasajero que «Da lástima ver tanto ingenio ocupado en versificar, sin entender lo que traen entre manos. Poetas hay de a sesenta y setenta ańos, tan idiotas como presumidos [...] sin más capacidad en los fines que en los principios» (Suárez de Figueroa 1913: 52).

Caso contrario tenemos en el fervoroso imitador del Cervantes de las Novelas ejemplares, Francisco de Lugo y Dávila: en la introducción de su Teatro popular (1622) encontramos uno de los primeros escritos teóricos sobre la novela.

Como podemos apreciar, pese a la importante difusión que ha alcanzado la obra de Cervantes, la preceptiva retórica del XVII no la incorpora en la misma medida, ni tampoco en los textos menos ortodoxos, donde sí hay algunas alusiones, pero marginales en conjunto, y en ningún caso como modelo de elocución o composición literaria.

Si los datos recogidos, a los que se pueden sumar otros muchos fuera del ámbito retórico (Rivas Hernández 1998: 35 y ss.), muestran la influencia y el conocimiento de la obra cervantina en esta centuria, ¿por qué las retóricas del XVII silenciaron a Cervantes? Sabemos que la producción novelística decayó a finales del $\mathrm{XVII}^{9}$, pero ¿en qué medida es la retórica una disciplina interesadamente permeable a la producción literaria contemporánea? ¿Qué justifica la atención a unos poetas en detrimento de otros, a unos prosistas en demérito de otros? Hay un factor importante que podríamos llamar «canon personal», como hemos visto en las abundantes citas que introduce Jiménez Patón de su buen amigo Lope, pero, aparte de estos gustos personales, de las propias lecturas o conocimientos de los autores, estas presencias o, en este caso, estas ausencias, reflejan una concepción de la retórica fundamentalmente elocutiva, que rentabiliza más la cita poética tradicional que la de la prosa de ficción. El que esta última careciera todavía de consideración teórica, el que no contara con antologías de relieve, o el que primara una visión tan poco favorable de los efectos y valores de la novela, serán aspectos determinantes en la incorporación de ejemplos literarios recientes de este género.

\section{LA INCORPORACIÓN DE Cervantes A LA RETÓRICA EN EL SIGLO XVIII}

Pese a los datos mencionados sobre la recepción de Cervantes en el siglo XVII, no será hasta el XVIII cuando asistamos a su despegue definitivo, tanto por el número de ediciones, imitaciones, traducciones e influencias, como por la abundancia y calidad de los trabajos críticos sobre su obra y los descubrimientos

8. Así lo sugiere Suárez Figaredo (2004: 189 y ss) cuando alude a las opiniones que vierte Figueroa en El Pasajero sobre Cervantes y Lope.

9. Pueden verse algunas explicaciones sobre este hecho en Álvarez Barrientos (1991: 12 y ss). 
sobre su vida, coincidiendo todo ello con su creciente incorporación a los tratados y la aparición de los primeros estudios serios sobre el autor ${ }^{10}$.

Un paso importante en su institucionalización lo tenemos en su pronta inclusión en el Diccionario de Autoridades (1726-1739), que lo reconoció en el corpus de referencias modélicas en prosa para ilustrar muchas de sus voces. Es más, en la "Historia de la Academia» del volumen primero se pone a Cervantes como ejemplo por su fina elocuencia:

De aquí se infiere la impropiedad del dicterio con que nos han motejado algunos Extranjeros, que llamaron monstruos al celebrado místico Fray Luis de Granada, al chistoso Quevedo, al ingenioso Cervantes, al discreto Calderón, y a otros; porque estos no fueron en la lengua monstruos, sino estudiosos y felices en el modo con que la usaron: y así pudieron manifestar al mundo lo que comprehende nuestro Idioma, y lo mucho que pierde el descuido, e aliño de aquellos, que no reparando en limar su estilo, abandonan el primor de engañar sus escritos en el oro finísimo de la elocuencia. (Diccionario de Autoridades I, 1726: XI)

De este modo, a la sólida nómina de "demóstenes españoles», como se califica a Fr. Luis de Granada, Fr. Luis de León, Ribadeneira, Quevedo, Calderón o Antonio Solís, se suma un no menos vigoroso corpus de "césares", tomados por la Academia como «Maestros de la Lengua»: Miguel de Cervantes, Diego de Saavedra y Juan de Mariana, entre otros muchos (Diccionario de Autoridades I, 1726: XI).

Para la mayoría de los críticos dieciochescos el Quijote era una sátira, y don Quijote, un personaje ridículo, extravagante y loco, que ofrecía una imagen distorsionada de España. Así lo vieron el P. Isla, Cándido M.a Trigueros, García de la Huerta, Erauso y Zabaleta, Joseph Carrillo, etc. (Rey Hazas y Muñoz Sánchez 2006: 19). Otros, como Nasarre y Montiano, apostaron por el de Avellaneda cuando promovieron su edición del Quijote en 1732, a cargo de la Real Academia ${ }^{11}$. Su convencimiento de que esta superaba la segunda parte del Quijote cervantino se fundaba en la naturalidad de sus aventuras, verosimilitud y semejanza de los personajes con los de la primera parte de la novela, y estilo ingenioso. Entre quienes lo defendieron estaban acreditados hombres de letras como Forner, Jovellanos, Cadalso, Samaniego, o Moratín.

10. Véase la amplia introducción sobre el origen del cervantismo en el XVIII de Rey Hazas y Ramón Muńoz Sánchez (2006: 13-87). Para más datos sobre las reediciones de la obra cervantina, véase Fernández Insuela (1993). Para la difusión internacional de Cervantes en el XVIII, remitimos a Aguilar Piñal, que habla de las cincuenta ediciones que se hicieron del Quijote en Francia y las cuarenta y cuatro en Inglaterra, más otras tantas en Alemania, Holanda, Italia, Bélgica, Rusia, Portugal, etc. A ello se ha de sumar su enorme repercusión en la producción literaria de estos países y la abundancia de imitaciones (veinticuatro en la literatura francesa, diecisiete en la alemana y quince en la inglesa). Puede verse en Aguilar Piñal (1983: 158-159).

11. Se trata de La vida y hechos del Ingenioso Hidalgo don Quijote de La Mancha, que contiene su cuarta salida y es la quinta parte de sus aventuras... Nuevamente añadido y corregido en esta imprenta por el Licenciado D. Isidro Perales y Torres, Madrid, Hermanos de Francisco Lasso, 1732, con prólogo de Montiano en defensa de Avellaneda. La primera edición apareció en Tarragona, Felipe Roberto, 1614. 
También fue incorporado a las historias de la literatura (Andrés, Lampillas, Marchena....) y a las antologías (Cuevas Cervera 2010). Su canonización desde esta perspectiva de la crítica no fue fácil y no permaneció al margen de la polémica en un siglo en el que esta se erigió en medio habitual de reivindicación literaria del gusto y del valor de las obras. Los criterios de esta reivindicación fueron diversos. No solo se tuvieron en cuenta factores estético-literarios, sino también morales e ideológicos para que Cervantes adquiriera el estatus de clásico.

Pero, ¿qué ocurrió con la preceptiva? La preceptiva española empieza a considerar las obras de Cervantes a partir del primer tercio del siglo XVIII, en el que sobresale el papel desempeńado por Mayans y Siscar, el gran responsable de la consideración teórica de Cervantes en la retórica de la época. Su interés por Cervantes data de sus primeros escritos, en los que figuraba como modelo de inventiva y estilo, a pesar de los resquicios latinos de algunos pasajes ${ }^{12}$. Sin embargo, y pese a alguna observación de detalle de este tipo, Cervantes es referente de primer orden en la ficción narrativa -junto a Saavedra y Quevedopor sus aptitudes para el entretenimiento y la pureza y suavidad de su estilo, aventajando incluso a Heliodoro, según el erudito de Oliva (Mayans y Siscar 1739: 163-164).

Este temprano interés de Mayans por el autor del Quijote tuvo la oportunidad de materializarse diez años después en el encargo que recibió, siendo bibliotecario de Felipe V, del ministro inglés Lord John Carteret para escribir la biografía de Cervantes (Martínez Mata 2004). Al no disponer de más documentos, tuvo que basarse sobre todo en sus escritos, a los que recurrió con el rigor habitual que caracterizó su producción filológica e historiográfica. Esta biografía, que será el trabajo más reeditado de Mayans -con más de diez ediciones en su siglo- tuvo enorme repercusión dentro y fuera de nuestras fronteras, inauguró un modelo de edición del Quijote precedido de su vida (Rey Hazas y Muñoz Sánchez 2006: 29-30), y actuó como una contrarréplica a la reciente edición que promovieran Nasarre y Montiano del Quijote de Avellaneda. De este modo, con su defensa del mérito literario del Quijote hacía también frente a las ideas que sobre Cervantes predominaban en los grupos intelectuales de la Corte (Mestre 1978).

Estos trabajos de Mayans favorecieron un enfoque teórico más libre de su producción literaria, menos sujeto a las limitaciones de una preceptiva deudora de la tradición poética y retórica anterior ${ }^{13}$. De esa manera Mayans valoró los distintos géneros cultivados por Cervantes al hablar de la ficción poética en prosa con los mismos parámetros que los demás géneros poéticos. No obstante,

12. Nos referimos a su Oración en alabanza de las Obras de don Diego Saavedra Fajardo (1725 y reeditada en sus Ensayos oratorios, Madrid, 1739), y en su Oración en que exhorta a seguir la verdadera idea de la elocuencia española (1727, publicada junto a otros textos del mismo autor en varias ocasiones a lo largo del XVIII).

13. Resultan imprescindibles los trabajos de López sobre las aportaciones de Mayans y de la retórica a la teoría de los géneros en la época: López (2000 y 2004). Sobre las ideas literarias de Mayans, remitimos también a Pérez Magallón (1991). 
en el análisis que hace Mayans de la obra cervantina se advierten con claridad los débitos retóricos de una crítica que fundamenta la perfección de un libro en «la buena invención, debida disposición y lenguaje proporcionado al asunto de que se trata». A la invención remite el propósito de la obra, el estudio de los personajes, la estructura y la técnica narrativa; a la buena disposición le corresponde el mérito de entrelazar los hechos con un artificio capaz de mantener la atención del lector; y a su estilo, el que cultive todas las modalidades de manera apropiada:

Según lo dicho ya se vè quén admirable es la Invencion de esta grande Obra. No lo es menos la Disposicion de ella; pues las devidas proporciones, i cada una ocupa el lugar que le toca: los Sucesos están enlazados con tanto artificio, que los mas llaman a los otros; i todos llevan suspensa i gustosamente entretenida la atención del Letor. En orden al Estilo ojala que el que hoy se usa en los asuntos mas graves fuesse tal. En èl se ven bien distinguidos, i apropiados los generos de hablar. [...] En suma el estilo de Cervantes en esta Historia de Don Quijote, es puro, natural, bien colocado, suave, i tan emendado, que en poquissimos Escritores Espańoles se hallarà tan exacto. De suerte que es uno de los mejores textos de la Lengua Española. (Mayans y Siscar 1737: 25)

No extraña por ello que se haya destacado el estilo de Cervantes como uno de los pilares de la admiración dieciochesca hacia el escritor. Como hemos mencionado antes, a pesar de reconocerse Mayans como uno de los más apasionados admiradores de Cervantes, no deja por ello de censurar algunos defectos menores, como los frecuentes anacronismos del Quijote o la introducción de demasiados episodios en el Persiles, aspectos estos que siempre tienen alguna disculpa. Dice al respecto:

Don Quijote es hombre de todos los tiempos, i verdadera Idèa de lo que ha avido, ai, i avrà: i assi se acomoda bien a todos los tiempos, i lugares. I quando los mas severos Críticos no admitan esta disculpa; a lo menos no me negaràn que estos descuidos, i los demás que fuera fácil añadir, de falsas alusiones, i equivocaciones, que suelen ser mas freqüentes en una mente algo abstrahida por la demasiada atención al principal assunto; por otra parte se recompensa con mil perfecciones; pudiéndose decir con verdad, que toda Obra es una Satira de la mas feliz, que hasta hoy se ha escrito, contra todo genero de gentes. (Mayans y Siscar 1737: 68)

Pero las opiniones de Mayans no discrepan tanto de la recepción generalizada del Quijote en la mayoría de los teóricos de la época (Torres Villarroel, Cándido M. ${ }^{a}$ Trigueros, Fr. Martín Sarmiento, Lampillas, Sempere y Guarinos, Juan Andrés, Forner...), que, impregnados del didactismo propio del Dieciocho, resaltan los efectos de la lectura incontrolada de los libros de caballerías y detallan la amenidad y las bondades de la obra, aunque también sus fallos e inverosimilitudes en la concatenación de los hechos, tiempos, lugares o situaciones, tal y como se aprecia en la relación de anacronismos que ofrece de la obra cervantina (Mayans y Siscar 1737: 58 y ss.). Aunque muchos de ellos son disculpados ante la grandeza de sus méritos, son detalles que revelan no solo una lectura detenida de sus obras, sino también la importancia del concepto clásico de verosimilitud en la crítica del momento. 
Desde los intereses de la poética neoclásica, ni el género novelístico ni Cervantes contaron con el protagonismo esperado. Ignacio de Luzán solo trató en su Poética (1737) de dramática, épica y lírica o mélica; y Burriel en su Compendio del arte poética, publicada veinte años después (1757), se fijó en los mismos géneros que su predecesor. Y otro tanto se puede decir de Díez González (1793), que tampoco trató de la novela.

Es lógico, por tanto, que en estas obras Cervantes tenga una presencia muy escasa, y que, cuando aparezca, lo haga más como modelo de estilo o composición dentro del canon poético. Así, en la Poética de Luzán, de 1737 y $1789\left(2^{\text {a ed. }}\right)^{14}$, en la que aparece citado diecinueve veces, se sitúa a Cervantes en el amplio grupo de los «excelentes poetas» que florecieron después de Boscán y Garcilaso, en el capítulo dedicado al «origen y progresos de la poesía vulgar». $Y$ en ese mismo capítulo, Cervantes es nuevamente citado junto a Quevedo y a Lope como adalid de estilo natural, frente a la afectación culterana.

El «famoso Cervantes», como se refiere a él Luzán, es también citado entre el grupo de pseudo-teóricos, de "los que hablaron por incidencia», de los que reflexionaron sobre la poesía sin escribir una poética específica, lo que le confirma en la idea de que la poesía antigua castellana «no tuvo jamás poética, ni reglas», y que nació «en brazos de la ignorancia vulgar, se crió entre las guerras y galanterías, sin cultura, sin arte, sin preceptos y sin crítica» (Luzán 2008: 174-180). Cervantes, pues, es mencionado no como novelista, sino como teórico, y esta faceta, apoyada en la autoridad de Luzán, será una de las que se prolongue en otros autores.

Las otras referencias en Luzán vienen de sus observaciones sobre el teatro, al tratar de los orígenes, progresos y estado actual de nuestro teatro, y a él sigue de cerca cuando habla de Lope de Rueda o Naharro, criticando la excesiva indulgencia de sus apreciaciones sobre Cervantes (Luzán 2008: 444 y ss.).

En la estela de Luzán, Díez González apenas cita a Cervantes en sus Instituciones poéticas, en las que el Quijote aparece como ejemplo moderno, junto con Quevedo, de sátira menipea (Díez González 1793: 191). Y es al hablar de este género cuando alaba el uso acertado, oportuno y discreto del arcaísmo en el habla de don Quijote, que sirve para ridiculizar los libros de caballería (Díez González 1793: 26). Su referencia, por tanto, es de índole estilística.

En este contexto, la Rethórica de Mayans (1757) se presenta a mediados del XVIII como la retórica más completa en cuanto a su planteamiento teórico y representación de la literatura nacional, como muestran las más de ciento veinte referencias a escritores españoles diferentes. Entre ellos el más citado es, con diferencia, Saavedra, con cerca del centenar de referencias, seguido de Fr. Luis de León (en torno a ochenta), y de Mateo Alemán, Cervantes y Góngora con cifras

14. Las doce autoridades españolas que contabiliza Sebold en la primera edición de la Poética de Luzán quedan muy lejos del sólido aparato erudito de Mayans y de la segunda edición de la misma Poética, de 1789, explicado por Demerson (1981: 272) como reflejo de la evolución intelectual de Luzán tras la experiencia francesa. 
muy próximas (entre treinta y cinco y cuarenta citas). Le siguen Santa Teresa y Hurtado de Mendoza, superando la treintena, y con más de veinte, Lope y Garcilaso.

La novedad importante con respecto a otros tratados de la época es que Mayans sí dio cabida a lo fingido y no dejó de ilustrar su teoría con ejemplos de novelas (Álvarez Barrientos 1983 y Aradra 2014). Así lo hizo cuando habló del diálogo fingido en el Quijote (Mayans y Siscar 1757: II, 460-461) o de las descripciones poéticas o fingidas, las que permitían más licencias, como la descripción del Siglo de Oro (Mayans y Siscar 1757: II, 481). La novela cervantina es para el erudito de Oliva todo un arsenal de ejemplos de las diferentes modalidades discursivas y de los más diversos procedimientos retóricos: ironía, onomatopeya, amontonamiento, paréntesis, gradación, paragoge, valores semánticos de sonidos, incisos, alteraciones en el orden de las palabras, estilo frío, gracia en el hablar, diálogo, descripciones, razonamiento fingido. Además, Cervantes era un autor que tenía muy trabajado, y esto le resultó de gran ayuda para escribir su Rhetórica.

\section{Cervantes en la teoría de la ElOCuCión Dieciochesca}

El otro pilar teórico en el que se asienta la reivindicación de Cervantes lo encontramos en la Filosofía de la elocuencia de Antonio de Capmany. Pese a la importancia que tiene en el XVIII en la apreciación teórica a la prosa, no deja de sorprender que en la primera edición de esta obra, de 1777, Cervantes aparezca citado solo una vez. El autor del Quijote es puesto como ejemplo de que el ingenio puede suplir a la memoria, pero no al contrario, según corroboraba la creación ficticia de este personaje como fruto de la imaginación, sin basarse en una historia real previa (Capmany 1777: 15).

Sin embargo, en la segunda edición de la Filosofía de la elocuencia, de 1812, Capmany aumentó significativamente el número de referencias cervantinas a veinticuatro. Entre ambas ediciones había publicado su Teatro histórico-crítico de la elocuencia española (1786-1794), y este le sirvió de base para sus ejemplos. Pero ¿qué Cervantes se cita? ¿Qué aspectos se privilegian?

En un tratado limitado a la elocución como este, Cervantes es ejemplo de "pintura con palabras» en el retrato de la felicidad y simplicidad de la edad de oro, de armonía de la frase, de reflejo de los arrebatos o pasiones que alteran el orden de los pensamientos y de las palabras por medio del hipérbaton, de estilo sencillo, de repetición, de gradación, de invocación, de descripciones, de ejemplos de historia, de prosopopeya, de símil y de alegoría ${ }^{15}$.

La defensa de Capmany de la naturalidad, y su desconfianza de la retórica al uso, le hace empatizar con un Cervantes puesto muchas veces como ejemplo de ingenio natural y modelo de elocución. No de otro modo se entiende su crítica a José Luis Munárriz, traductor de las Lecciones sobre la Retórica y las

15. Capmany (1812: 30, 95, 168-69, 257, 363, 373, 446, 474, 502, 526, 584 y 615, respectivamente). 
Bellas Letras de Blair, por censurar a «nuestros Marianas, Leones, Cervantes, Argensolas, Saavedras y Solises, en cuyos escritos, se propusieron dar lecciones de retórica á la nación» (Capmany 1812: 219-220).

Nos encontramos, pues, con la primera retórica que aborda de manera monográfica la potencialidad estilística de la prosa cervantina. Denominada significativamente Filosofia de la elocuencia, la obra se centraba en la elocución y su propósito contra el enfoque escolástico, repetitivo y trasnochado de la retórica de su tiempo, reivindicador del ejemplo, de la ilustración detenida de los procedimientos estilísticos..., favoreció sobremanera esta amplia utilización de los textos cervantinos.

Como hemos adelantado antes, su Teatro histórico-crítico le había proporcionado a Capmany un amplio material. Ya en el discurso preliminar del primer tomo justificaba la necesidad de establecer un canon, de separar valores y calidades, de realzar las perfecciones de los autores con la misma franqueza que se notaban los descuidos. "¿Quién osaria hoy, sin nota de blasfemo, descubrir defectos de estilo, por exemplo, en Mariana, en Cervantes, en los dos Luises?» -se preguntaba- (Capmany 1786-1794: vol. I, pp. XIX-XX).

Además, el haber cultivado la poesía era una ventaja para la prosa numerosa y brillante de Fr. Luis de León, Cervantes, Lope de Vega, Bartolomé Leonardo de Argensola, y Solís, ya que su perfección procedía en buena medida de la poesía, según él ${ }^{16}$.

Aparte de estas alusiones sueltas, en el volumen IV de su antología Capmany dio una lista de voces anticuadas que afectaron Mariana y Cervantes, y dedicó a Cervantes cien páginas (Capmany 1786-1794: vol. IV, pp. 410-510), incluida una biografía. En ellas reconocía que "pocos autores ha tenido España mas desatendidos en vida que Miguel de Cervantes, y ninguno tan celebrado después de muerto» (Capmany 1786-1794: vol. IV, p. 418). Esta imagen del escritor maltratado por la vida, pero agasajado por la fama se repetirá en varias ocasiones. Capmany reconoce sin paliativos el mérito universal de Cervantes, y de él ofrece una selección de fragmentos como modelo de descripciones y razonamientos de diverso tipo. El motor de su reivindicación reside, pues, en el mérito de su estilo y de su lenguaje:

No puedo disputar, ni aun dudar, si la famosa fábula del Quixote merece un lugar de los mas distinguidos en el templo de las musas, por la novedad de su objeto, por lo bien manejada que está la acción, por la fecunda variedad de sus episodios, por la propiedad de sus caracteres, por la naturalidad y gala de su narración, y por la solidez de su moral. Mi oficio se reduce á presentar á Cervantes por la parte del lenguaje castellano, y calidades de su variado estilo: entresacando del tesoro de sus obras pedazos muy preciosos de excelentes pinturas y descripciones, ya tiernas ya fuertes, ya risueñas ya terribles; y de relaciones y razonamientos, unos familiares otros sublimes, unos amenos y otros patéticos, unos serios y otros jocosos (Capmany 1786-1794: vol. IV, pp. 426-427).

16. Así lo había reconocido el propio Cervantes en el prólogo de La Galatea, que cita Capmany (1786-1794: I, CXLVI-CXLVII). 
Desde esta perspectiva destaca la «pureza y propiedad de la dicción» y la «claridad y hermosura de la frase» como el principal mérito del estilo de Cervantes. El Quijote se caracteriza, pues, por un estilo sencillo, natural y equilibrado, conveniente a la materia de su fábula, y ameno, o dicho de otra manera, "sencillo sin languidez, llano sin baxeza, y popular sin indecencia»" Asimismo, se destaca su dominio del habla familiar, su armonía, variedad de tonos y afectos y cultivo de todos los géneros de estilo, que lo convierten en modelo para el aprendizaje de la lengua castellana, a pesar de algunos borrones sueltos en su prosa debidos a la uniformidad de estilo y rodeos en la narración (Capmany 1786-1794: vol. IV, pp. 434-35).

Así, pues, la selección de fragmentos que hace Capmany es sobre todo de relaciones y pinturas, retratos personales y morales, pinturas políticas y morales del carácter y vida de ciertas gentes, estados y profesiones, discursos, oraciones y razonamientos serios y jocosos, pinturas alegóricas de vicios y virtudes. Se trata, por tanto, de textos ejemplares en ejercicios de estilo, que dejan al margen a un Cervantes más dinámico, creador de historias y ficciones ${ }^{18}$.

\section{OTRAS RETÓRICAS DEL SIGLO XVIII}

Fuera de estos dos casos, en el resto de las retóricas del siglo XVIII hallamos una presencia dispar de Cervantes. Los condicionantes antes señalados sobre la lengua de los tratados, la ubicación de la retórica en una enseñanza protagonizada en gran medida por las órdenes religiosas y orientada a un alumnado muy joven, influyó en el enfoque y referentes utilizados, entre los que costaba admitir como modelo a un escritor de novelas.

Así, el Tratado de Rhetórica para uso de las escuelas de Manuel Merino (1775), o los reeditadísimos Elementos de Retórica del P. Calixto Hornero (1777), apenas mencionan a Cervantes, y cuando lo hacen es muy de pasada, junto a otras plumas contemporáneas o clásicas. Merino recomendó la lectura de los autores latinos del Siglo de Oro (Cicerón, Tito Livio, Cornelio Nepote, Salustio, Virgilio, Horacio...) y en castellano de los escritores del siglo de Felipe II: Fr. Luis de Granada, Maestro León, Juan de Ávila, Zurita, Mariana, Rodríguez, Solís, Mendoza, Cervantes, Santa Teresa, Garcilaso, Ercilla, Villegas, Lope, Velasco, Rebolledo...

Hornero, por su parte, apostó por el modelo latino de Cicerón y el castellano de Fr. Luis de Granada, aunque de forma similar a Merino citó a Cervantes como modelo de estilo y lengua literaria. De estilo mediano y florido cita la Historia de la Nueva España de Solís, los Claros varones de Fernando del Pulgar, las Guerras de Granada de Mendoza y Don Quijote de Cervantes

17. Dice Capmany (1786-1794: IV, 428): «En el estilo del Quixote se vió trocada la hinchazón y vanidad de nuestras antiguas fábulas en simplicidad y solidez, la groseria en decoro, el desaliño en compostura, la dureza en elegancia, y la aridez en amenidad».

18. Así lo ha destacado también Cuevas Cervera (2010: 111). 
(Hornero 1802: 199-200). En esta línea, para adquirir un buen estilo en el lenguaje recomendó leer con mucho cuidado y observación obras de Fr. Luis de Granada, Fr. Luis de León, Juan de Ávila y Santa Teresa, o bien a Zurita, Cervantes, Mendoza, Morales, Garibay, Román u otros escritores de los muchos que escribieron con mucha propiedad en tiempo de Carlos I, Felipe II y Felipe III (Hornero 1802: 204). En este caso lo que sí encontramos es una restricción de las referencias al ámbito de la prosa, del que excluye los vocablos, frases y locuciones propias de los poetas, como dos ámbitos estilísticos claramente diferenciados (Hornero 1802: 122).

Ya en la última década del siglo, el escolapio Joaquín Traggia hizo en su Rhetórica filosófica (1793) alguna alusión suelta a las novelas como ejemplo de imitación universal en prosa, con lo que dejaba entreabierta una consideración teórica de este género, que todavía no incorpora. Así se desprende cuando admite que obras como Don Quijote demostraban que el verso no era esencial a la poesía, lo que autorizaba en cierta medida su estatuto literario (Traggia 1793: 181).

En cuanto al Tratado de la elocución de Madramany (1795), como en el caso de Capmany, se recurre a Cervantes sobre todo como ejemplo de elocución. Ejemplifica estilos y recursos estilísticos con sus obras más representativas: $L a$ Galatea, el Quijote, el Persiles, las Novelas Ejemplares... Y aunque cultive todos los géneros y estilos, se refiere a él como modelo de lo satírico-moral, donde es muy recomendable por su elegancia Mateo Alemán «y el nunca bastantemente elogiado Miguel de Cervantes, cuyo estilo es puro, natural, propio, fácil, claro, fluido y ameno» (Madramany y Calatayud 1795: 24-25).

A él reprocha asimismo cierta tendencia latinista en La Galatea, al imitar la colocación del verbo al final de la frase (Madramany y Calatayud 1795: 29). Pero otros muchos méritos estilísticos centran su atención, como el número y armonía del principio de "La fuerza de la sangre», la etopeya y la mímesis, el manejo de los estilos en el Quijote, el estilo asiático en el famoso discurso de Don Quijote a los cabreros, el estilo hinchado cuando escribe "Apenas había el rubicundo Apolo tendido por la faz de la ancha y espaciosa tierra las doradas hebras de sus hermosos cabellos [...]", el diálogo ameno, gracioso y elegante entre Cipión y Berganza, o el estilo epistolar en la carta de Luscinda a Cardenio ${ }^{19}$.

En definitiva, la retórica del XVIII descubre en los textos cervantinos todo un arsenal discursivo de estilos y de procedimientos estilísticos que lo rentabilizan como un modelo extremadamente versátil de prosa natural, variada y amena. Sus aportaciones específicas en el terreno del género y de la composición se producirán más en otros entornos críticos: prólogos, ensayos, ediciones, estudios varios..., textos en los que, desde los márgenes de la preceptiva más ortodoxa, sus autores se pronunciaron sobre la novela y las aportaciones de Cervantes al género en invención, dominio de los episodios y de la estructura,

19. Puede verse en Madramany y Calatayud (1795: 67-68, 82-83, 85, 96, 142-143, 181, 181-182, respectivamente). 
tratamiento de los personajes, originalidad, excelencia estilística y amenidad. Así lo vemos en el abate Juan Andrés, en Lampillas, Vicente de los Ríos y en tantos otros, en los que su obra empieza a verse con la dimensión de un clásico.

El paso definitivo lo encontramos cuando la confluencia entre retórica y poética que se empieza a materializar en el periodo de entre siglos, incorpore de manera definitiva la novela a los géneros en prosa. Es muy significativo que en la traducción-adaptación de las Lecciones sobre la retórica y las bellas letras de Hugh Blair realizada por José Luis Munárriz (1798-1801), Cervantes se convierta en el autor español más citado, con casi treinta de referencias, seguido de cerca por Lope, Fr. Luis de León y Garcilaso, superando todos ellos la veintena de citas. Y otro tanto apreciamos en los Principios filosóficos de la literatura traducidos y adaptados por García de Arrieta de la obra de Batteux, en los que presta no menos atención a la cuestión de los géneros, distribuidos en prosa y elocuencia y en poesía (García de Arrieta 1797-1805: IX, 408). Con más de sesenta referencias, el autor más citado es Lope, seguido de Herrera, Calderón y Garcilaso, y a continuación, con más de treinta, Cervantes. Para García de Arrieta, con Granada, León, Pérez de Oliva, Hernando del Pulgar y Cervantes llegó a mejorarse nuestra lengua hasta alcanzar su máximo grado de perfección (García de Arrieta 1797-1805: IX, 186).

Gran conocedor y editor de la obra de Cervantes, García de Arrieta preparó incluso una selección de dichos e ideas destacadas de Fénelon y Cervantes, sobre quien publicó El espiritu de Miguel de Cervantes Saavedra o la filosofía de este grande genio $(1814)^{20}$. Cervantes se convirtió en el representante por antonomasia de la novela, a la misma vez que seguirá siendo modelo de lengua y estilo, como vemos en el Diccionario de tropos y figuras de Igartuburu (1842), en el que todos sus ejemplos están tomados de Cervantes. Del silencio con que la preceptiva respondió en un primer momento ante el autor del Quijote, llegamos a la creciente y consolidada atención que se le presta ya desde los primeros estadios del XIX, cuando recurren a él con frecuencia Sánchez Barbero (1805), Lista (1821), Urcullu (1826), Gómez Hermosilla (1826) o Martínez de la Rosa (1827), por citar solo algunos (Aradra 2000: 226 y ss.).

\section{PARA FINALIZAR}

Como hemos visto, aunque la retórica sea el escenario histórico de la prosa, todavía en el XVII mostró su resistencia a la incorporación de autores contemporáneos que cultivaron la prosa de ficción. Los grandes hitos que muestra la trayectoria de la incorporación cervantina a esta preceptiva nos revelan de qué manera el discurso normativo sanciona muy a posteriori los méritos de un autor como Cervantes. A diferencia de lo que ocurre con la poesía, la prosa de ficción, la novela en particular, no entra con pleno derecho

20. Sobre la importancia de esta antología de textos en forma de diccionario moral, se remite al estudio introductorio que hace Francisco Cuevas Cervera en su edición de la misma (García de Arrieta, 2008); sobre el cervantismo de García de Arrieta, véase Cuevas Cervera (2007). 
en la retórica hasta que no empieza a ser aceptado el género, bien entrado el XVIII, y con él su máximo representante.

En el recorrido que hemos realizado se ha podido comprobar cómo el protagonismo de la elocutio entre las partes de la retórica del siglo XVII privilegió un canon fundamentalmente poético, no narrativo. A pesar del amplio conocimiento y difusión en la época del autor del Quijote, esta resistencia inicial de la teoría retórica a la incorporación de Cervantes como modelo pasa por una creciente valoración estilística de su prosa y de la novela como género.

Así, la situación central de un autor en el canon literario no resta importancia al estudio del proceso que lo sitúa en ese lugar ${ }^{21}$. Por ello la retórica ofrece un campo de sumo interés en el estudio de la recepción literaria de determinadas épocas, ya que las aperturas históricas de su basamento tradicional resultan extremadamente iluminadoras de cómo se adapta a las nuevas circunstancias e intereses literarios. De este modo, y en términos generales, también la historia de esta permanencia nos ha hecho contemplar una vez más la historicidad de los valores artísticos y la resistencia que opone todo clásico a ser administrado por cualquier canon.

\section{Bibliografía}

Aguilar Piñal, Francisco, "Cervantes en el siglo XVIII», Anales Cervantinos, XXI, 1983, pp. 153-163.

Álvarez Barrientos, Joaquín, «Algunas ideas sobre teoría de la novela en el siglo XVIII en Inglaterra y España», Anales de Literatura Española, 2, 1983, pp. 5-23.

Álvarez Barrientos, Joaquín, La Novela del siglo XVIII, Madrid, Júcar, 1991.

Aradra Sánchez, Rosa M.a, De la retórica a la teoría de la literatura (siglos XVIII y XIX), Murcia, Servicio de Publicaciones de la Universidad de Murcia, 1997.

Aradra Sánchez, Rosa M. ${ }^{a}$, «El canon en la literatura espańola (siglos XVIII y XIX)», en José M. a Pozuelo y Rosa M. Aradra (eds.), Teoría del canon y literatura española, Madrid, Cátedra, 2000, pp. 141-303.

Aradra Sánchez, Rosa M.a, «Cicerón ilustrado. La recepción de su obra en la retórica española del siglo XVIII», Revista de Estudios Latinos, 11, 2011, pp. 185-205.

Aradra Sánchez, Rosa M.a « «Retórica y novela: notas sobre una canonización genérica» en Domingo Sánchez-Mesa, José Manuel Ruiz Martínez y Azucena González Blanco (eds.), Teoría y comparatismo: tradición y nuevos espacios, Granada, Universidad de Granada, 2014, pp. 305-316.

Artaza, Elena, El ars narrandi en el siglo XVI español, Bilbao, Universidad de Deusto, 1989.

Artaza, Elena, «Casos, quaestiones y otros recursos retóricos al servicio de la educación en el Quijote», en Ana Vián Herrero y Consolación Baranda Leturio (eds.), Letras humanas y conflictos del saber: la Filología como instrumento a través de las edades, Madrid, Editorial Complutense, 2008, pp. 303-323.

21. Puede verse el caso similar que plantea la permanencia de Cicerón en la retórica espańola del XVIII, en Aradra (2011: 185-205). 
Blecua, Alberto, «Cervantes y la retórica (Persiles, III, 17)», en Alberto Blecua et alii; estudios coordinados por Aurora Egido, Lecciones cervantinas, Zaragoza: Caja de Ahorros y Monte de Piedad de Zaragoza, Aragón y Rioja, 1985, pp. 131-147.

Capmany, Antonio de, Filosofía de la elocuencia, Madrid, Antonio Sancha, 1777.

Capmany, Antonio de, Teatro histórico-critico de la eloqüencia española, Madrid, Antonio Sancha, 1786-1794, 5 vols.

Capmany, Antonio de, Filosofía de la elocuencia, 2a ed., Londres, Longman, Hurst, Rees, Orme y Brown, 1812.

Correa Calderón, Evaristo, Baltasar Gracián: su vida y su obra, Madrid, Gredos, 1970.

Cuevas Cervera, Francisco, «El cervantismo de Agustín García de Arrieta», Insula, 727 728, 2007, pp. 10-11.

Cuevas Cervera, Francisco, "Cervantes en la configuración del canon de literatura española: Antologías y colecciones de literatura (1750-1850)», en Victoriano Gaviño Rodríguez y Fernando Durán López (eds.), Gramática, canon e historia literaria (1750-1850), Madrid, Visor, 2010, pp. 85-115.

Demerson, George, "Un aspecto de las relaciones hispano-francesas en tiempo de Fernando VI: las Memorias literarias de París de Ignacio de Luzán (1751)», en Textos y Estudios del Siglo XVIII, no 9, 1981, pp. 241-273.

Díez González, Santos, Instituciones poéticas, Madrid, Benito Cano, 1793.

Fernández Insuela, Antonio, «Sobre la narrativa española de la Edad de Oro y sus reediciones en el siglo XVIII", Revista de Literatura, LV, 109, 1993, pp. 55-84.

Galbarro García, Jaime, «Hacia una catalogación de las retóricas españolas más importantes del siglo XVII. Modelos, tendencias y canon poético», en Begoña López Bueno (ed.), El canon poético en el siglo XVII, Sevilla, Universidad de Sevilla, 2010, pp. 73-92.

García de Arrieta, Agustín de, Principios filosóficos de la Literatura... Obra escrita en francés por el Señor Abate Batteux, Madrid, Antonio Sancha, 1797-1805, 9 vols.

García de Arrieta, Agustín de, El espiritu de Miguel de Cervantes Saavedra: la filosofía de este grande genio..., ed. de Francisco Cuevas Cervera, Sevilla, Renacimiento, 2008.

Gracián, Baltasar, Arte de ingenio, Madrid, Juan Sánchez, 1642.

Hebrera y Esmir, Antonio, Jardín de la eloquencia, Zaragoza, Herederos de Diego Dormer, 1677. ed. Edición de Félix Monge, Zaragoza, Universidad de Zaragoza, 1959.

Hornero, Calixto, Elementos de Retórica, Valencia, Benito Monfort, 1777. 4. ${ }^{\text {a }}$ Impresión, Madrid, Benito Cano, 1802.

Igartuburu, Luis de, Diccionario de tropos y figuras, Madrid, Imp. de Alegría y Charlain, 1842.

Jiménez Patón, Bartolomé, Elocuencia española en arte, ed. de Francisco J. Martín, Barcelona, Puvill Libros, 1993.

López, François, «Las malas lecturas. Apuntes para una historia de lo novelesco», Bulletin Hispanique, 100, n. 2, 1998, pp. 475-514.

López, François, «La institución de los géneros literarios en la España del siglo XVIII», Bulletin Hispanique, 102, n. 2, 2000, pp. 473-517.

López, François, «Sobre los géneros y otros conceptos de la crítica en la España moderna», Bulletin Hispanique, 106, n. 1, 2004, pp. 317-350. 
López Grigera, M. ${ }^{a}$ Luisa, «El Quijote a la luz de Hermógenes», Salina, n 6, 1991, pp. 34-40.

López Grigera, M. ${ }^{a}$ Luisa, La retórica en la España del Siglo de Oro, Salamanca, Universidad de Salamanca, 1994.

Lugo y Dávila, Francisco de, Teatro popular: novelas morales para mostrar los géneros de vidas del pueblo, Madrid, Vda. de Fernando Correo Montenegro, 1622. Edición de Emilio Cotarelo y Mori, Madrid, Viuda de Rico, 1906.

Luzán, Ignacio de, La Poética, ed. de Russell P. Sebold, Madrid, Cátedra, 2008.

Madramany y Calatayud, Mariano, Tratado de la elocución, Valencia, Hermanos Orga, 1795.

Martí, Antonio, La preceptiva retórica española en el Siglo de Oro, Madrid, Gredos, 1972.

Martín Jiménez, Alfonso, «El Quijote de Cervantes, el Quijote de Avellaneda y la Retórica del Siglo de Oro», Edad de Oro, 19, 2000, pp. 171-188.

Martínez Mata, Emilio, «Un cervantista por encargo: Gregorio Mayans y Siscar (16991781)", Boletín de la Asociación de Cervantistas, I, 1, 2004, pp. 15-21.

Mayans y Siscar, Gregorio, Vida de Miguel de Cervantes Saavedra, Londres, J. y R. Tonson, 1737.

Mayans y Siscar, Gregorio, Ensayos oratorios, Madrid, Juan de Zúñiga, 1739.

Mayans y Siscar, Gregorio, Rhetórica, Valencia, Herederos de Gerónimo Conejos, 1757, 2 vols.

Merino, Manuel, Tratado de Rhetórica, Madrid, Juan Antonio Lozano, 1775.

Mestre, Antonio, El mundo intelectual de Mayans, Valencia, Ayuntamiento de Oliva, 1978.

Monge, Félix, "Una retórica aragonesa de fines del siglo XVII», en Gracián y su época, Zaragoza, Institución Fernando el Católico, 1986, pp. 103-116.

Montero Reguera, José, El Quijote y la crítica contemporánea, Alcalá de Henares, Centro de Estudios Cervantinos, 1997.

Montero Reguera, José, El Quijote durante cuatro siglos: lecturas y lectores, Valladolid, Universidad de Valladolid, 2005.

Munárriz, José Luis, Lecciones sobre la Retórica y las Bellas Letras, traducidas y adicionadas a partir del original inglés de Hugh Blair, Madrid, Antonio Cruzado, 1798-1801, 4 vols.

Peralta, Ceferino, "La ocultación de Cervantes en Baltasar Gracián», en Gracián y su época. Actas de la I Reunión de Filólogos Aragoneses, Zaragoza, Instituto Fernando el Católico, 1986, pp. 137-156.

Pérez Magallón, Jesús, En torno a las ideas literarias de Mayans, Alicante, Instituto de Cultura «Juan Gil-Albert», 1991.

Pozuelo, José M. ${ }^{\mathrm{a}}$ y Rosa M. ${ }^{\mathrm{a}}$ Aradra (eds.), Teoría del canon y literatura española, Madrid, Cátedra, 2000.

Rey Hazas, Antonio y Juan Ramón Muñoz Sánchez (eds.), El nacimiento del cervantismo. Cervantes y el Quijote en el siglo XVIII, Madrid, Verbum, 2006.

Rivas Hernández, Ascensión, Lecturas del Quijote (siglos XVII-XIX), Salamanca, Colegio de España, 1998.

Robles, Juan de, El culto sevillano, Sevilla, Imp. de El Mercantil Sevillano, 1883. 
Roldán, Antonio, D. Quijote: del Triunfalismo a la Dialéctica, Murcia, Publicaciones de la Universidad de Murcia, 1975 [Anales de la Universidad de Murcia. Filosofía y Letras, vol. 33, n. 1, 2, 3 y 4].

Roldán, Antonio, «Cervantes y los paradigmas de la retórica clásica», en Cervantes, su obra y su mundo. Actas del I Congreso Internacional sobre Cervantes, Madrid, EDI-6, 1981, pp. 47-58.

Rozas, Juan Manuel, «El lopismo de Jiménez Patón Góngora y Lope en la Elocuencia española en arte», Revista de Literatura, 21, 1962, pp. 35-54.

Suárez de Figueroa, Cristóbal, Plaza universal de todas ciencias y artes, Madrid, Luis Sánchez, 1615.

Suárez de Figueroa, Cristóbal, El pasajero. Advertencias utilísimas a la vida humana, Madrid, Luis Sánchez, 1617. Edición de Francisco Rodríguez Marín, Madrid, Renacimiento, 1913.

Suárez Figaredo, Enrique, Cervantes, Figueroa, y el crimen de Avellaneda, Barcelona, Ediciones Carena, 2004.

Traggia, Joaquín, Rhetórica filosófica, Zaragoza, Vda. de Francisco Moreno, 1793.

Vilanova, Antonio, "Preceptistas españoles de los siglos XVI y XVII", en Historia general de las literaturas hispánicas, dirigida por G. Díaz Plaja. Barcelona, III, 1953, pp. 667-671. 
